\title{
Efeito do resfriamento sobre a textura post-mortem da carne do peixe matrinxã Brycon cephalus
}

[Chilling effect on the post-mortem texture of the matrinxã fish muscle Brycon cephalus]

\author{
H. Suárez-Mahecha ${ }^{1}$, L.H. Beirão ${ }^{2}$, A. Francisco ${ }^{2}$, L.S.O. Nakaghi ${ }^{3}$, S.C. Pardo-Carrasco ${ }^{4}$ \\ ${ }^{1}$ Faculdad de Ciencias Agropequaria - UNALMED \\ Calle 59 n. 63-20 \\ Medellin - Colombia \\ ${ }^{2}$ Departamento de Ciência e Tecnologia de Alimentos - UFSC - Florianópolis, SC \\ ${ }^{3}$ Faculdade de Ciências Agrárias e Veterinárias - UNESP - Jaboticabal, SP \\ ${ }^{4}$ Centro de Investigación Piscícola - Universidad de Córdoba - Montería, Colômbia
}

\begin{abstract}
RESUMO
Os mecanismos que causam o amolecimento e a perda na textura post-mortem da carne de matrinxã foram determinados por meio das mudanças na microestrutura do músculo, imediatamente após a morte e depois de 12 horas de estocagem a $-3^{\circ} \mathrm{C}$. As observações na microestrutura, realizadas com microscópio eletrônico de transmissão, foram semelhantes aos resultados obtidos na força de ruptura do músculo medidos com o texturômetro. Os valores da força da ruptura foram menores para a carne após o resfriamento. Observou-se que as fibras do colágeno do tecido conectivo pericelular se desintegraram e que as do colágeno do tecido conectivo do miocommata conservaram sua arquitetura e integridade. Houve pouca degradação da linha Z. Isso sugere que o amolecimento post-mortem da carne de mantrinxã, durante a estocagem a $-3^{\circ} \mathrm{C}$, é causado pela degradação do tecido conectivo pericelular.
\end{abstract}

Palavras-chave: peixe, matrinxã, Brycon cephalus, textura, colágeno, tecido conectivo

\begin{abstract}
In order to determine the mechanisms that cause the post mortem muscle softness of the matrinxã Brycon cephalus, changes in the micro structure of the muscle were observed immediately after death and after 12 hours of storage at $-3^{\circ} \mathrm{C}$, measuring the firmness of the flesh with test instruments. Observations by the transmission electron microscope were similar to the results obtained in the breaking strength of the muscle measured with a texturometer. The values of the breaking strength of the fish muscle were smaller after chilling. At the same time, it was observed that the collagen fibers of the pericellular connective tissue had disintegrated, while the collagen fibers of the miocommata connective tissue maintained their organization and integrity. No evident breakdown of Z-discs was observed. It is suggested that the postmortem tenderization of the matrinxã muscle during chilled storage was due to the disintegration of the collagen fibers in the pericellular connective tissue and, in a smaller extent, to the weakening of Z-disk.
\end{abstract}

Keywords: fish, matrinxa, Brycon cephalus, texture, collagen, connective tissue

\section{INTRODUÇÃO}

A firmeza é um fator muito importante para avaliação da qualidade da carne de peixe, principalmente no momento da comercialização. Sabe-se que a carne de peixe amolece depois de 24 horas de armazenamento em baixas temperaturas (Mochizuki e Sato, 1996).

Alguns estudos foram realizados principalmente em peixes marinhos para avaliar a causa do amolecimento post-mortem na carne dos peixes, sendo poucos em espécies de água doce, como os

Recebido em 08 de junho de 2005

Aceito em 27 de março de 2007

E-mail: hsuarezm@unal.edu.co 
realizados em carpa (Cyprinus carpio) e truta (Oncorhynchus mykiss, Salmo irideus) (Ando et al.,1999).

O colágeno é o maior constituinte do tecido conectivo intramuscular dos peixes e, como tem sido demonstrado, exerce um importante significado na textura da carne de peixes (Sato et al., 1986). Estudos histológicos têm demonstrado que o tecido conectivo pericelular é degradado mais intensamente durante a armazenagem a baixas temperaturas do que o tecido conectivo intersticial (Hallett e Bremner, 1988; Ando et al., 1995; Kubota et al., 1996).

Sabe-se que existem distintos colágenos, química e geneticamente diferentes, entre os mesmos indivíduos (Bornstein e Sage, 1980). No tecido conectivo pericelular dos peixes, é reconhecida a existência do colágeno tipo $\mathrm{I}$ e, em maior proporção, do colágeno tipo $\mathrm{V}$, este último indicado como responsável pela textura post-mortem (Sato et al., 1997; Shigemura et al., 2004). O colágeno tipo $\mathrm{V}$ aparece identificado pelo seu diâmetro menor nos estudos de microscopia eletrônica de transmissão (Sato et al., 1997; Ando et al., 1999). Já se demonstrou que o diâmetro da fibra de colágeno diminui com o incremento do colágeno tipo V (Birk et al., 1990).

A firmeza do músculo também é um importante índice de frescor, e o amolecimento indica deterioração da qualidade da carne. Desse modo, faz-se necessário conhecer os mecanismos do amolecimento, para desenvolver métodos que possam ser utilizados na piscicultura, a fim de prevenir esse processo de perda da qualidade na textura da carne. Algumas pesquisas relacionam esse fenômeno a certas espécies cultivadas em viveiro mais do que a espécies capturadas no meio natural (Ando et al., 1999; Alasalvar et al., 2002).

No Brasil, a produção de peixes de viveiro tem aumentado e o matrinxã é uma das espécies mais procuradas para esse fim (Pezzato et al., 1994; Guimarães e Storti Filho, 1997). No entanto, desconhecem-se as causas do amolecimento postmortem na armazenagem em baixas temperaturas, nesse peixe. $O$ objetivo deste trabalho foi determinar a possível desintegração do tecido conectivo pericelular e sua relação com a perda de textura em matrinxã.

\section{MATERIAL E MÉTODOS}

Utilizaram-se matrinxãs de três tamanhos, com peso médio e comprimento médio de $120 \mathrm{~g}, 230 \mathrm{~g}$, e
$350 \mathrm{~g}$ e $15 \mathrm{~cm}, 18 \mathrm{~cm}$ e $22 \mathrm{~cm}$, respectivamente. Os peixes foram criados e cultivados em viveiro e abatidos por meio de punção no cérebro. Imediatamente depois de mortos, retiraram-se amostras do músculo dorsal para análise microscópica. $\mathrm{O}$ restante dos peixes foi empacotado em sacola de polietileno e armazenado a $-3^{0} \mathrm{C}$ durante 12 horas. Utilizaram-se três peixes para cada tamanho.

A textura da carne foi determinada no músculo dorsal, segundo Ando et al. (1992), em uma amostra de $10 \mathrm{~mm}$ de espessura. Foi registrada a máxima força de penetração, com êmbolo cilíndrico de $3 \mathrm{~mm}$ de diâmetro, que foi forçado a entrar na fatia de músculo, paralelo à orientação de suas fibras, à velocidade de $60 \mathrm{~mm} / \mathrm{min}$. Os resultados foram expressos como força à ruptura, mostrados pela média de cinco a oito medições. $\mathrm{O}$ aparelho empregado foi $o$ analisador de textura ${ }^{1}$. As medições foram feitas antes e após o esfriamento.

Para microscopia eletrônica de transmissão (TEM), as amostras de músculo dorsal $(1 \mathrm{~mm} \times 1 \mathrm{~mm} \times$ $5 \mathrm{~mm}$ ) foram fixadas em glutaraldeído $2,5 \%$ por 2 horas, lavadas várias vezes em tampão fosfato de sódio $0,1 \mathrm{M}, \mathrm{pH} 7,2$; pós-fixadas em tetróxido de ósmio a $1 \%$, por 2 horas, em seguida, lavadas no mesmo tampão e desidratadas com passagens em soluções de concentrações crescentes de etanol: $50 \%, 60 \%, 70 \%, 80 \%, 90 \%, 100 \%$ e $100 \%$ por 20 minutos em cada uma dessas soluções. O procedimento seguinte foi a infiltração, iniciada com a imersão das amostras numa mistura de araldite e etanol puro (1:1) por 12 horas, à temperatura ambiente.

A inclusão foi realizada em mistura plena de resina araldite. $\mathrm{O}$ material incluído foi colocado na estufa à temperatura de $60^{\circ} \mathrm{C}$ por 72 horas, para efetuar a polimerização. Após, foram feitos cortes de $0,3 \mu \mathrm{m}$ para análise e seleção das áreas a serem observadas à microscopia eletrônica. Esses cortes foram corados com azul de toluidina a $1 \%$ em ácido bórico saturado. Tais cortes foram também observados e selecionados, e os melhores fotomicrografados com auxílio de fotomicroscópio. Seguindo esse procedimento, cortes ultrafinos com $70 \mathrm{~nm}$ de espessura foram obtidos em ultramicrótomo ${ }^{2}$, com navalha de vidro, montados em grade de cobre e contrastados com acetato de uranila e citrato de chumbo e, então, observados e

\footnotetext{
${ }^{1}$ TA-XT2 - Stabble Micro Sistems - Haslewere, UK

${ }^{2}$ Ultracut - Leicva - Tóquio, Jpn.
} 
fotografados em microscópio eletrônico de transmissão ${ }^{3}$ com uma aceleração de $80 \mathrm{kv}$.

O delineamento experimental foi em fatorial $2 \times 3$ (dois tipos de resfriamento $\mathrm{x}$ três pesos de peixe). Para os valores da textura (força de ruptura), foi feita análise de variância e, em caso de diferença estatística, teste Tukey para comparação de médias. O nível de significância adotado foi de $\mathrm{P}<0,05$.

\section{RESULTADOS E DISCUSSÃO}

Os resultados da força de ruptura encontram-se na Tab. 1. A firmeza do músculo diminuiu significativamente depois de 12 horas de resfriamento $(\mathrm{P}<0,001)$.

Também foram comparados os resultados da força de ruptura dependendo do tamanho dos peixes utilizados, mas não foram observadas diferenças significativas, que pudessem associar o grau de perda de firmeza com o peso dos peixes utilizados. No entanto, observou-se tendência no aumento da força de ruptura à medida que aumentou o peso do matrinxã (dados não mostrados). Segundo Love et al. (1972) e (1992), o colágeno do miocommata dos peixes velhos é mais débil e tem menos ligações cruzadas que o colágeno dos peixes jovens. No presente estudo, entretanto, utilizaram-se somente peixes jovens, pois o matrinxã só é adulto quando alcança de 3-4kg (Graef et al., 1987).

A microestrutura do músculo do peixe matrinxã foi observada por microscopia eletrônica de transmissão (TEM), mostrada nas Fig. 1 a 3. A observação das fibras de colágeno no tecido conectivo pericelular indicou que elas mantêm estreita relação com o amolecimento postmortem da carne de peixe armazenada a baixas temperaturas (Sato et al., 1997; Ando et al., 1999). No músculo, imediatamente após a morte (Fig. 1a), as fibras de colágeno do tecido conectivo pericelular são observadas claramente, mantendo uma arquitetura ordenada junto à fibra muscular. Depois do armazenamento durante 12 horas a $-3^{0} \mathrm{C}$ (Fig. 1b), as fibras do tecido conectivo pericelular se desintegraram, observando-se perda do arranjo arquitetônico em relação à fibra muscular.

${ }^{3}$ Jeol JEM - 1010 - Tóquio, Jpn.
Verificou-se simetria das fibras de colágeno no tecido conectivo pericelular (Fig. 2a) imediatamente após a morte. Na fig. 2b, observase $o$ efeito do armazenamento em baixa temperatura sobre o tecido conectivo pericelular, sendo que as fibras de colágeno apresentam-se completamente degradadas e não é possível determinar a simetria da fibra.

Não foi verificada alteração ou degradação em nenhuma das fibras de colágeno no tecido conectivo do miocommata, depois do tempo de armazenamento utilizado neste estudo. O diâmetro da fibra de colágeno no tecido conectivo pericelular, de 20 a $28 \mathrm{~nm}$, é semelhante ao de outros estudos (Sato et al., 1997; Ando et al., 1999).

A desintegração das fibras de colágeno no tecido conectivo pericelular mostra relação com a diminuição na força de ruptura obtida no teste instrumental, fato conhecido como amolecimento post-mortem. O amolecimento post-mortem da carne de matrinxã pode ter sido causado pela desintegração das fibras de colágeno do tecido conectivo pericelular.

A microestrutura da fibra muscular é mostrada na Fig. 3. No músculo em estado fresco (Fig. 3a), a linha $\mathrm{Z}$, localizada no centro dos filamentos de actina pode ser identificada. Entretanto, após o armazenamento (fig. 3b), há dificuldade na observação da estrutura da linha $Z$ e pode-se apreciar certa perda do arranjo.

Durante o manuseio e a armazenagem em baixas temperaturas, a união dos blocos musculares ao miocommata poderia falhar, causando 0 fenômeno conhecido por "gaping" (Love et al., 1969; Skjervold et al., 2002) e, segundo esses autores, dois tipos de "gaping" são conhecidos. $\mathrm{O}$ primeiro acontece durante o congelamento em estado de rigor mortis e é atribuído ao enfraquecimento das conexões de colágeno devido à formação de cristais de gelo (Badii e Hotel, 2002). Nesta pesquisa, os peixes foram resfriados em estado de pré-rigor. A causa do segundo tipo de "gaping" pode acontecer ao longo do tempo em peixes armazenados. 


\section{Suárez-Mahecha et al.}

Tabela 1. Médias e desvios-padrão da força de ruptura antes e depois do resfriamento em matrinxã de três pesos distintos, medidos com texturômetro

\begin{tabular}{lccc} 
& \multicolumn{3}{c}{ Peso dos peixes } \\
\cline { 2 - 4 } & $120 \mathrm{~g}$ & $230 \mathrm{~g}$ & $350 \mathrm{~g}$ \\
\hline Antes do resfriamento & $211,8 \pm 16,9 \mathrm{a}$ & $196,4 \pm 6,8 \mathrm{a}$ & $242,3 \pm 23,5 \mathrm{a}$ \\
Depois do resfriamento & $116,5 \pm 11,5 \mathrm{~b}$ & $83,0 \pm 2,1 \mathrm{~b}$ & $102,1 \pm 6,5 \mathrm{~b}$ \\
\hline
\end{tabular}

* Valores seguidos de letras distintas na linha e na coluna indicam diferenças $(\mathrm{P}<0,001)$.

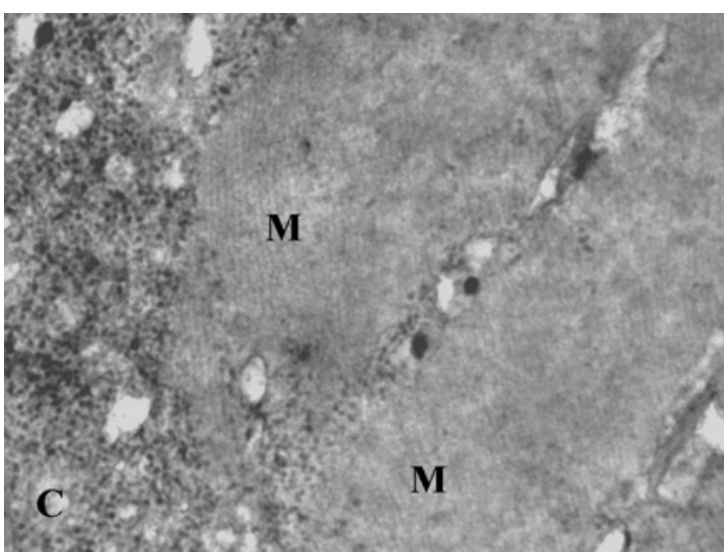

a

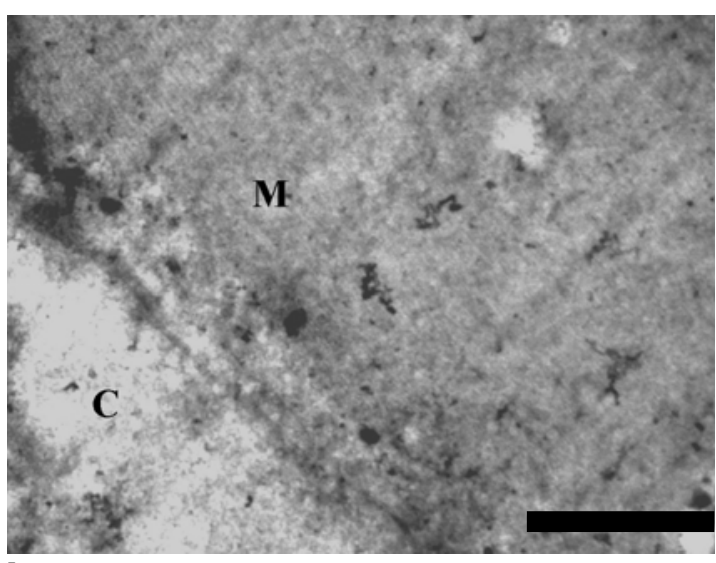

b

Figura 1. Mudanças na microestrutura do colágeno pericelular no músculo de matrinxã. (a) Fibra muscular e colágeno em estado fresco. (b) Perda da arquitetura da fibra muscular e degradação do colágeno depois de 12 horas de armazenamento a $-3^{0} \mathrm{C}$. M: Fibra muscular; C: fibras de colágeno (a barra representa $500 \mathrm{~nm})$.

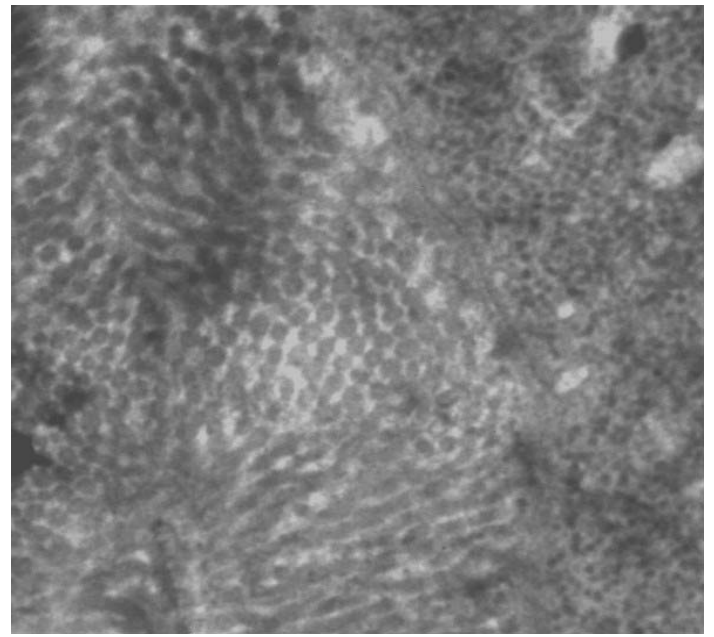

a

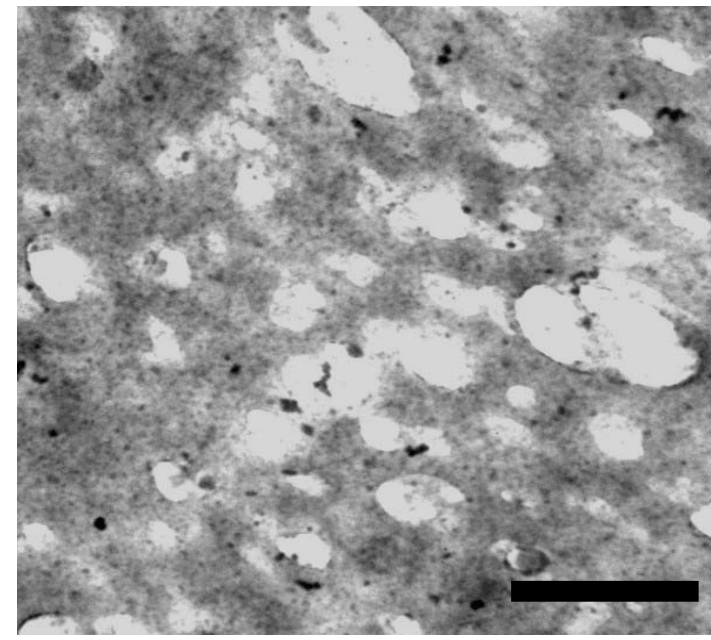

b

Figura 2. Tecido conectivo pericelular no músculo de matrinxã. (a) Fibras de colágeno em estado fresco após a morte. (b) Fibras de colágeno completamente degradadas após a armazenagem em baixa temperatura durante 12 horas (a barra representa 500nm). 


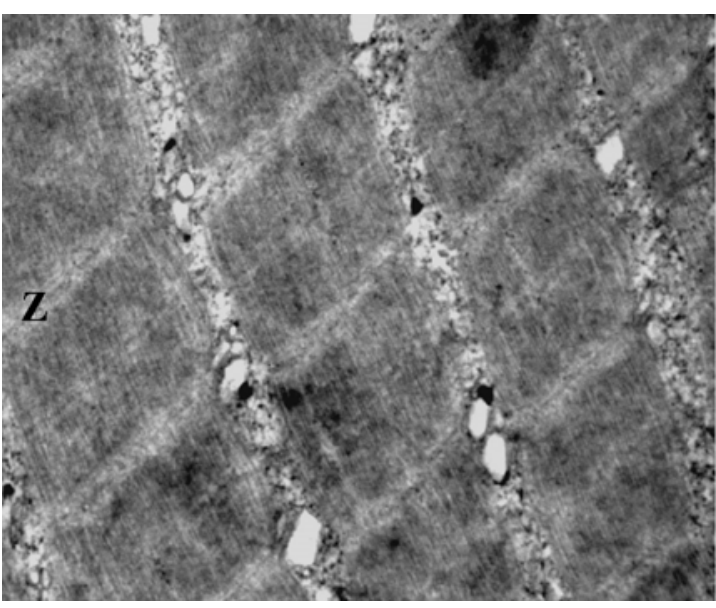

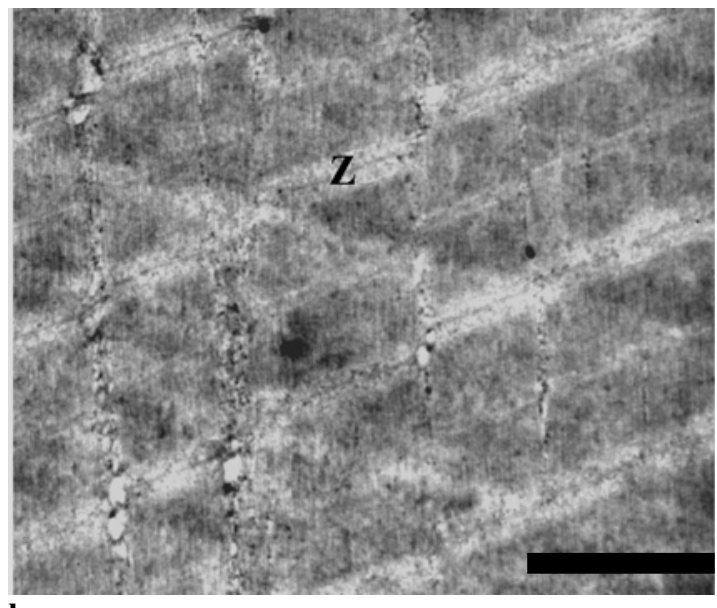

b

Figura 3. Cortes longitudinais da miofibrila muscular. (a) Nota-se claramente a linha Z, em estado fresco. (b) Depois do armazenamento as linhas $\mathrm{Z}$ apresentam-se pouco definidas. (a barra representa $500 \mathrm{~nm}$ ).

Hallett e Bremner (1988) determinaram que o "gaping", causado pela degradação das fibras de colágeno entre a fibra muscular e o miocommata, foi o responsável pelo amolecimento do músculo de "hoki" (Macruronus novaezelandiae), embora os autores não tenham realizado testes de firmeza no músculo. Ando et al. (1992) sugeriram que a relação entre "gaping" e amolecimento do músculo permanece pouco clara. Se o "gaping" tem estreita relação com o amolecimento do músculo, no peixe "hoki" há a possibilidade de causar o amolecimento relativamente tardio, quando comparada a outros peixes (Oka et al., 1990; Ando, 1997), porque não foram observadas mudanças no músculo de "hoki" após 24 horas de armazenamento. No presente estudo, não foram encontradas mudanças nas fibras de colágeno do miocommata que possam relacionar o amolecimento do músculo do matrinxã a algum tipo de "gaping".

Os filamentos de conectina são compostos por $\alpha$ conectina altamente elásticos e tendo como função a conexão das linhas $\mathrm{Z}$ com o filamento de miosina. Kumano e Seki (1993) demonstraram a desintegração dos filamentos de conectina, por meio da diminuição de $\alpha$ conectina, o que aconteceu rapidamente quando os músculos da carpa (Cyprinus carpio) e da truta arco íris (Oncorhynchus mykiss) alcançaram a temperatura de armazenamento a $2^{0} \mathrm{C}$, embora continuasse ocorrendo diminuição da força de ruptura dos músculos da primeira, após o descongelamento, mesmo depois de ter havido degradação completa da $\alpha$-conectina. No músculo da truta arco-íris, a força da ruptura diminuiu mais rapidamente que em $\alpha$-conectina. Estes resultados sugerem que existem outros fatores adicionais relacionados com 0 amolecimento post-mortem. Neste estudo, não foram feitas observações histológicas e não foram realizados testes bioquímicos com os filamentos de conectina. Outros autores também sugeriram que as mudanças nas fibras de conectina modificaram as estruturas do músculo (Sato et al., 1997).

Tem sido demonstrado que o diâmetro da fibra de colágeno no tecido conectivo pericelular varia de 20 a $30 \mathrm{~nm}$ e corresponde ao colágeno tipo V, presente em maior quantidade (Birk et al., 1990; Ando et al., 1999). No amolecimento da carne de diferentes peixes, Sato et al. (1997) indicaram o colágeno tipo $\mathrm{V}$ como o principal constituinte no tecido conectivo pericelular, sendo responsável pelo amolecimento post-mortem. No entanto, o motivo pelo qual acontece, preferencialmente, a degradação desse colágeno ainda não está claro. Yamashita e Konagaya (1991a, 1991b) relataram que a catepsina $\mathrm{L}$ foi a responsável pelo amolecimento da carne de salmão chum, encontrando fagócitos ao redor das fibras musculares. Nesta pesquisa, não foram observados fagócitos ao redor das fibras degradadas de colágeno e no tecido conectivo pericelular, semelhante ao resultado encontrado por Ando et al. (1999). Outra possível hipótese propõe que os peptídeos que contêm hidroxiprolina, possivelmente como produto da degradação do colágeno, poderiam ser 
quantificados e serviriam como indicadores da degradação do colágeno. Ando et al. (1999) não encontraram diferenças nos níveis de hidroxiprolina em peixes pelágicos e demersais, porque a molécula de colágeno pode ser degradada em uma região onde o colágeno não está presente. Kubota et al. (2003) consideraram as metaloproteinases como responsáveis pelos processos proteolíticos, gerando a degradação dos colágenos tipo I e V.

Mesmo que possam existir outros fatores envolvidos no amolecimento post-mortem da carne de matrinxã, pode ser conveniente iniciar estudos comparados de espécies provenientes de viveiro e de ambiente natural nativas do Brasil.

\section{CONCLUSÕES}

O amolecimento da carne do peixe matrinxã é causado pela degradação do tecido conectivo pericelular, como efeito do resfriamento a $-3^{\circ} \mathrm{C}$ durante 12 horas. As observações histológicas coincidem com a perda significativa da textura, medida no texturômetro.

\section{REFERÊNCIAS BIBLIOGRÁFICAS}

ALASALVAR, C.; TAYLOR, K.D.; SHAHIDI, S. Comparative quality assessment of cultured and wild sea bream Sparus aurata stored in ice. J. Agi. Food Chem., v.50, p.2039-2045, 2002.

ANDO, M. Softening mechanism of fish meat. Suisangaku Series. Kouseisha Kouseikaku, v.114, p.73-82, 1997.

ANDO, M.; NISHIYABU, A.; TSUKAMASA, $Y$. et al. Post-mortem softening of fish muscle during chilled storage as affected by bleeding. $J$. Food Sci., v.64. 3, p.423-428, 1999.

ANDO, M.; TOYOHARA, H.; SAKAGUCHI, M. Post-mortem tenderization of rainbow trout muscle caused by the disintegration of collagen fibers in the pericellular connective tissue. Bull. Jpn. Soc. Sci. Fish., v.58, p.567-570, 1992.

ANDO, M.; YOSHIMOTO, Y.; INABU, K. et al. Post-mortem change of three-dimensional structure of collagen fibrillar network in fish muscle pericellular connective tissues corresponding to post-mortem tenderization. Fish. Sci., v.61, p.327-330, 1995.

BADII, H.; HOTEL, N.H. Changes in the texture and structure of cod and haddock fillets during frozen storage. Food Hidrocol., v.16, p.313-319, 2002.

BIRK, D.E.; FITCH, M.J.; BABIARZ, P.I. et al. Fibrogenesis in vitro: interaction of type I and $\mathrm{V}$ collagen regulates fibril diameter. J. Cell. Sci. v.95, p.649-657, 1990.

BORNSTEIN, H.; SAGE, H. Structurally distinct collagen types. Ann. Rev. Bioch., v.49, p.957-1003, 1980.

GRAEF E.W.; RESENDE E.K.; PETRY P. et al. Policultivo de matrinchã (Brycon sp) y jaraqui (Semaprochilodus sp) en pequenas represas. Acta Amaz., v.16/17, p.42, 1987.

GUIMARÃES, S.F.; STORTI FILHO, A. The effects of temperature on survival of young Matrinchã Brycon cephalus under laboratory conditions. In: INTERNACIONAL SYMPOSIUM BIOLOGY OF TROPICAL FISHES, 41., 1997, Manaus. Anais...Manaus, 1997. p.41. (Resumo).

HALLETT, C.I.; BREMNER, A.H. Fine estructure of the myocommata muscle fiber junction in hoki Macruronus novaezelandie. J. Sci. Food Agric., v.44, p.245-261, 1988.

KUBOTA, M.; KINOSHITA, M.; TAKEUCHI, $K$. et al. Solubilization of type I collagen from fish muscle connective tissue by matrix metalloproteinase-9 at chilled temperature. Fish. Sci., v.69, p.1053-1059, 2003.

KUBOTA, S.; SATA, K.; OHSTSUKI, K. et al. Degradation de $\alpha$-connectin in raw fish muscle and softening evaluated by breaking strength occur independently during one chilled storage. Fish. Sci., v.3, p.600-602, 1996.

KUMANO, Y.; SEKI, N. Change in $\alpha$ connecting content during storage of iced, frozen, and thawed fish muscle. Nippon Suisan Gakkaishi, v.59, p.559-564, 1993.

LOVE, R.M. Biochemical dynamics and the quality of fresh and frozen fish, In: HALL, G.M. (Ed.). Fish processing technology. Glasgow: Blache Academic G. Prossional, 1992. p.1-27.

LOVE, R.M.; HAQ, M.; SMITH, G.L. The connective tissues of fish V. Gaping in cod of 
different sizes as influenced by a seasonal variation in the ultimate pH. J. Food Technol., v.7, p.281-290, 1972.

LOVE, R.M.; LAVETY, J.; STEEL, P.J. The connective tissues of fish 11. Gaping in commercial species of frozen fish in relation to rigor mortis. J. Food Technol., v.4, p.39-44, 1969.

MOCHIZUKI, S.; SATO, A. Effects of various killing procedures on post-mortem changes in the muscle of hose mackerel. Bull. Jpn Soc. Sci. Fish., v.64, p.276-279, 1996.

OKA, H.; OHNO, K.; NINOMIYA, J. Changes in texture during cold storage of cultured yellowtail meat prepared by different killing methods. Bull. Jpn. Soc. Sci. Fish., v.6, p.16731678. 1990.

PEZZATO, L.E.; BARROS, M.M.; DEL CARRATORE, C.R. et al. Avaliação do matrinxã Brycon cephalus mantido sob condições de clima sub tropical. In: SIMPÓSIO BRASILEIRO DE AQÜICULTURA, 8., 1994. Piracicaba. Anais...Piracicaba, 1994. p.62. (Resumo).

SATO, K.; ANDO, M.; KUBOTA, S. et al. Involvement of type $\mathrm{V}$ collagen in softening of fish muscle during short-term chilled storage. $J$. Agr. Food Chem., v.45, p.343-348, 1997.
SATO, K.; YOSHIMAKA, R.; SATO, M. et al. Collagen content in the muscle of fishes in association with their swimming movement and meat texture. Bul. Japan Soc. Scie. Fish., 52, p1595-1600, 1986.

SHIGEMURA, Y.; ANDO M.; OISHI, K. et al. Effect of inhabited sea area on chub mackerel meat texture and possible degradation of type $\mathrm{V}$ collagen during chilled storage. Fish. Sci., v.70, p.933-935, 2004.

SKJERVOLD, P.O.; FJERA, S.O.; OSTBY, P.B. et al. Live-chilling and crowding stress before laughter of Atlantic salmon Salmo salar. Aquaculture, v.192. p.265-280, 2002.

YAMASHITA, M.; KONAGAYA, S. Hydrolytic of salmon cathepsins $\mathrm{B}$ and $\mathrm{L}$ to muscle structural proteins in respect of muscle softening. Bull. Jpn. Soc. Sci. Fish., v.57, p.1917-1922, 1991a.

YAMASHITA, M.; KONAGAYA, S. Inmunohistochemical localization of cathepsins $\mathrm{B}$ and $\mathrm{L}$ in the white muscle of chum salmon Oncorhynchus keta in spawning migration: Probable participation of phagocytes rich in cathepsins in extensive muscle softening of the nature salmon. J. Agr. Food Chem., v.39, p.1402-1405, 1991b. 